ECOLOGICA, Vol. 28, No 101 (2021), 11-15

https://doi.org/10.18485/ecologica.2021.28.101.3

Originalni naučni rad

UDC: 582.099:581.9(497.11 Кошутњак)

\title{
Farmakodinamska svojstva lekovitih vrsta u okviru osam odeljenja SP „Šuma Košutnjak“
}

\section{Pharmacodynamic properties of medicinal plants within eight departments of NM „Šuma Košutnjak“}

\author{
Dušan Jokanović ${ }^{1}$, Jovana Petrović ${ }^{2}$, Predrag Inđić ${ }^{3}$, Dragica Stanković4, \\ Goran Trivan ${ }^{5}$, Jelena Urošević ${ }^{6}$, Milijana Marić ${ }^{7}$ \\ 1,2,3,7 Šumarski fakultet, Univerzitet u Beogradu, Beograd, Srbija \\ $1,2,3,7$ Faculty of Forestry, University of Belgrade, Belgrade, Serbia \\ 4,5Institut za multidisciplinarna istraživanja, Univerzitet u Beogradu, Beograd, Srbija \\ 4,5Institute for Multidisciplinary Research, University of Belgrade, Belgrade, Serbia \\ ${ }^{6}$ Elektroprivreda Srbije, Beograd, Srbija \\ ${ }^{6}$ Public Enterprize Electric Power Industry of Serbia, Belgrade, Serbia
}

Rad primljen: 18.01.2021, Rad prihvaćen: 27.02.2021.

Sažetak: U ovom radu sprovedena je analiza farmakodinamskih svojstava lekovitih biljaka u okviru osam odeljenja SP „Šuma Košutnjak“. Inventarisanjem lekovite flore na ovom području utrvđeno je prisustvo 101 lekovite vrste. $\mathrm{Na}$ osnovu opšteprihvaćene metodologije za analizu farmakodinamskih svojstava, svi lekoviti taksoni su svrstani u ukupno 14 grupa. Dobijeni rezultati farmakodinamske analize pokazuju dominaciju droga koje leče kardiovaskularni, digestivni i respiratorni sistem. Imajući u vidu značaj ovih istraživanja kako bi se, ne samo utvrdila brojnost i farmakodinamska svojstva prisutnih lekovitih vrsta, već i stvorila realna osnova za njihovo racionalno korišćenje u budućnosti, neophodno je nastaviti sa monitoringom na celokupnom području SP „Šuma Košutnjak“.

Ključne reči: SP „Šuma Košutnjak“, lekovite biljke, farmakodinamska svojstva, fitoterapija.

\begin{abstract}
In the paper was conducted analysis of pharmacodynamic properties of medicinal plants within eight departments of NM „Šuma Košutnjak“. Inventory of medicinal flora at this area established presence of total 101 medicinal plants. Baesd on generally accepted methodology for pharmacodynamic properties analysis, all medicinal taxa were classified in 14 groups. Obtained results show domination of the plants that treat cardiovascular, digestive and respiratory system. Bearing in mind the importance of this research, not only for establishing number and pharmacodynamic properties of medicinal plants, but also for creating a realistic basis for their reasonable utilization in the future, it is needed to continue with monitoring at the whole area of NM „Šuma Košutnjak“.
\end{abstract}

Key words: NM “Šuma Košutnjak“, medicinal plants, pharmacodynamic properties, phytotherapy.

${ }^{1}$ orcid.org/0000-0002-8143-4219, e-mail: dusan.jokanovic@sfb.bg.ac.rs

${ }^{2}$ orcid.org/0000-0001-6606-3897, e-mail: jovana.petrovic@sfb.bg.ac.rs

3orcid.org/0000-0003-3639-5385, e-mail:predragindjic@hotmail.com

${ }^{4}$ orcid.org/0000-0002-8577-953X, e-mail: dstankovic@imsi.bg.ac.rs

${ }^{5}$ orcid.org/0000-0002-7129-358X, e-mail: goran.trivan@imsi.bg.ac.rs

${ }^{6}$ orcid.org/0000-0001-5580-8283, e-mail: urosevicj75@gmail.com

7orcid.org/0000-0002-8995-4315, e-mail: student.milijanamaric1954011@sfb.bg.ac.rs 


\section{UVOD / INTRODUCTION}

Celokupno područje Balkanskog poluostrva odlikuje se velikim florističkim diverzitetom i bogatstvom vaskularne flore uz neizbežno prisustvo brojnih retkih, endemičnih, reliktnih i ugroženih vrsta, koje se od prirode ne mogu sresti ni na jednom drugom prostoru (Kojić, Vilotić, 2006). Na teritoriji Srbije je ukupno zabeleženo 3.562 biljne vrste i podvrste, pri čemu u kategoriju strogo zaštićenih divljih vrsta spada 606 , dok zaštićenih biljnih taksona ima 535 , što ukupno čini 1.141 individuu ili oko $1 / 3$ od ukupnog broja predstavnika vaskularne flore (Igić et al., 2010).

Treba napomenuti da brojne lekovite vrste imaju i izraženu sposobnost fitoremedijacije, tj. mogućnost fitoekstrakcije teških metala i samim tim sanacije kontaminiranog zemljišta, vode i vazduha (Stanković, Jokanović, 2016; Jokanović et al., 2017; Jokanović et al., 2018; Kerkez et al., 2019).

Spomenik prirode „Šuma Košutnjak“ predstavlja zaštićeno područje na teritoriji Republike Srbije koga odlikuju signifikantne prostorne funkcije, biološke vrednosti pod šumskom vegetacijom, ali predstavlja i prirodno stanište raznovrsne flore i faune, kao i objekata geološkog nasleđa koji imaju karakter prirodnih retkosti i veliki značaj za proučavanje geološke istorije grada Beograda. Teritoriju SP „Šuma Košutnjak" čini ukupno 24 odeljenja, a za potrebe ovog rada izdvojeno je 8 odeljenja koja se tipološki međusobno razlikuju u izvesnoj meri. U okviru ovih 8 odeljenja determinisan je ukupno 101 lekoviti takson, pri čemu taksonomska analiza pokazuje dominaciju familija Lamiaceae i Rosaceae (Jokanović et al., 2020).

Na zaštićenom području „Šuma Košutnjak“ su ustanovljena dva režima zaštite i to: režim zaštite II stepena koji obuhvata šume lužnjaka i graba kod Hajdučke česme na površini od 3.48 ha $(1.31 \%)$ i režim zaštite III stepena koji se prostire na preostaloj površini od 261 ha 77 ari $98 \mathrm{~m} 2$ (98.69\%). Ovo područje je povereno na upravljanje JP „Srbijašume“, Šumskom gazdinstvu „Beograd“, koje ispunjava zakonom propisane uslove u pogledu kadrovske, stručne i organizacione osposobljenosti za obavljanje poslova zaštite, unapređenja, promovisanja i održivog razvoja zaštićenog područja.

Što se tiče dosadašnjih florističkih istraživanja na području SP „Košutnjak“, utvrđeno je dominantno prisustvo lekovitih vrsta iz sledećih familija: Rosaceae, Brassicaceae, Lamiaceae, Violaceae i Ranunculaceae (Šarčević-Todosijević et al., 2018). U pojedinim radovima (llić et al., 1972) govori se o značajnom uticaju antropogenog faktora na biološku ravnotežu na ovom području, a ističe se i prisustvo jedne reliktne vrste - kostrike (Ruscus aculeatus), koja je nekada egzistirala na obalama nekadašnjeg Panonskog mora i preživela glacijaciju. Tipološki, šume istraživanog područja, zavisno od ekoloških uslova, mogu se izdiferencirati na 4 asocijacije: šume lužnjaka i graba; šume kitnjaka, cera i graba; šume cera i sladuna; šume medunca i crnog jasena.

Cilj ovog rada vezan je za utvrđivanje farmakodinamskih svojstava registrovanih lekovitih biljaka, kao i za mogućnost njihovog korišćenja u fitoterapiji.

\section{MATERIJALI I METODE / MATERIALS AND METHODS}

Pregled flore lekovitih biljaka na istraživanom području urađen je na osnovu literaturnih podataka o lekovitim taksonima na teritoriji SP „Šuma Košutnjak" (Jokanović et al., 2020). Sistematska klasifikacija lekovitih vrsta zaštićenog prirodnog dobra SP „Šuma Košutnjak“, u okviru 8 istraživanih odeljenja, izvršena je na osnovu njihovih farmakodinamskih svojstava, kao i mogućnosti upotrebe u svrhu fitoterapije. Postoje brojni literaturni izvori o farmakodinamskim svojstvima lekovitog bilja Srbije (Sarić, 1989; Ranđelović et al., 2002; Tucakov, 2014) i na osnovu njih, lekovite biljne droge se mogu klasifikovati u sledećih 14 grupa:

1. Droge koje deluju na kardiovaskularni sistem

2. Droge koje deluju na organe za varenje

3. Droge koje deluju na organe za disanje

4. Droge za lečenje centralnog i perifernog nervnog sistema

5. Droge koje deluju na autonomni nervni sistem

6. Droge za lečenje urogenitalnih organa

7. Droge za lečenje kožnih bolesti

8. Droge za regulisanje prometa materije

9. Antidijabetici

10. Antihistaminici

11. Fitoncidno bilje

12. Galaktagozi

13. Tonici

14. Droge za popravku ukusa i mirisa raznih lekova.

\section{REZULTATI I DISKUSIJA / RESULTS AND DISCUSSION}

$\mathrm{Na}$ području SP „Šuma Košutnjak“, u okviru istraživanih 8 odeljenja, detektovana je ukupno 101 lekovita vrsta:

Acer platanoides L., Achillea milefolium L., Aesculus hippocastanum L., Agrimonia eupatoria L., Agropyron repens (L.) Beauv., Ajuga reptans L., Allium ursinum L., Arctium lappa L., Artemisia 
vulgaris L., Asperula odorata L., Ballota nigra L., Bellis perennis L., Brassica alba L., Brassica nigra L., Campanula persicifolia L., Capsela bursapastoris (L.) Med., Cardamine bulbifera L., Chelidonium majus L., Clematis vitalba L., Conium maculatum L., Convallaria majalis L., Convolvulus arvensis L., Cornus mas L., Cornus sanguinea L., Coronilla varia L., Corylus avellana L., Crataegus monogyna Jacq, Daucus carota L., Epilobium parviflorum Schreb., Euphorbia amygdaloides L., Euphorbia cyparissias L., Evonymus europaeus L., Ficaria verna L., Fragaria vesca L., Fumaria officinalis L., Fraxinus ornus L., Galium verum L., Geranium robertianum L., Geum urbanum L., Glechoma hirsuta Waldst. et Kit., Hedera helix L., Helleborus odorus (L.) W.K., Hypericum perforatum L., Hyssopus officinalis L., Iris variegata L., Juglans regia L., Lamium maculatum L., Lamium purpureum L., Leonorus cardiaca L., Ligustrum vulgare L., Lonicera caprifolium L., Lysimachia vulgaris L., Malva silvestris L., Medicago sativa L., Mentha longifolia (L.) Huds., Oxalis acetosella L., Paeonia officinalis L., Papaver rhoeas L., Plantago lanceolata L., Plantago major L., Plantago media L., Polygonum aviculare L., Potentilla erecta (L.) Raeusch., Prunella vulgaris L., Prunus avium L., Prunus cerasifera Ehrh., Pteridium aquilinum (L.) Kuhn, Pulmonaria officinalis L., Pyrus piraster L., Quercus cerris L., Quercus pubescens Willd., Quercus robur L., Ranunculus repens L., Robinia pseudoacacia L., Rosa canina L., Rubus hirtus L., Rumex acetosella L., Ruscus aculeatus L., Salvia pratensis L., Sambucus nigra L., Sedum album L., Silene vulgaris (Moench.) Garcke, Stachys sylvatica L., Stellaria holostea (L.) Scop., Stellaria media (L.) Scop., Symphytum officinale L., Tamus communis L., Taraxacum officinale Web., Teucrium chamaedrys L., Tilia platyphyllos Scop., Trifolium pratense L., Trifolium repens L., Ulmus minor Mill., Urtica dioica L., Verbascum phlomoides L., Verbena officinalis L., Veronica chamaedrys L., Veronica persica Poir., Vicia cracca L., Viola alba L., Viola tricolor L.

Droge koje deluju na kardiovaskularni sistem

- Kardiotonici, kardiokinetici, kardijačni analeptici: Helleborus odorus, Urtica dioica

- Kardijačni sedativi: Crataegus monogyna, Leonorus cardiaca

- Vazokonstriktori i hipertenzori: Allium ursinum

- Vazodilatatori i hipotenzori: Crataegus monogyna, Hypericum perforatum, Sambucus nigra, Capsela bursa-pastoris, Daucus carota, Rosa canina, Prunella vulgaris
- Koronarni vazodilatatori: Capsela bursapastoris, Urtica dioica, Sambucus nigra

- Antivarikoze i antihemoroidalije: Achillea milefolium

- Antiemetici: Rosa canina, Rumex acetosella, Fragaria vesca, Malva silvestris

- Adstigencija, stiptici, konstipancija, antidijaroici: Achillea milefolium, Crataegus monogyna, Potentilla erecta, Fragaria vesca, Geum urbanum, Urtica dioica, Rumex acetosella, Hypericum perforatum, Rosa canina, Rubus hirtus, Salvia pratensis

- Holagoge i holeretici: Artemisia vulgaris, Chelidonium majus, Taraxacum officinale, Teucrium chamaedrys

- Antispazmodici, gastrointenstinalni sedativi: Daucus carota

- Antihelmintici i intenstinalne dezinficijencije: Daucus carota

Droge koje deluju na organe za varenje

- Sijalagoga, sudorifika: Sambucus nigra

- Amaro-tonika, stomahika, gastrična stimulacija: Artemisia vulgaris, Taraxacum officinale, Geum urbanum, Potentilla erecta, Ajuga reptans, Salvia pratensis, Achillea milefolium

- Karminativa: Achillea milefolium

- Purgancija, laksativa: Sambucus nigra, Agropyron repens

- Emetika: Verbascum phlomoides, Rosa canina

- Adstrigencija, stiptika, konstipancija, antidijaroika: Capsela bursa-pastoris, Geum urbanum, Prunella vulgaris, Quercus cerris, Acer platanoides, Cornus mas, Cornus sanguinea

- Holagoga i holeretika: Artemisia vulgaris, Taraxacum officinale, Chelidonium majus, Rosa canina

- Antispazmodika, gastrointestinalna sedativa: Daucus carota

- Antihelmintika i intestinalna dezificijencija: Daucus carota, Artemisia vulgaris.

Droge koje deluju na organe za disanje

- Antiseptika i balsamika: Hypericum perforatum, Malva silvestris, Quercus cerris, Corylus avellana, Salvia pratensis

- Ekspektorancija i emoliencija: Malva silvestris, Sambucus nigra, Verbascum phlomoides, Viola alba, Plantago lanceolata 
- Bronhijalna spazmolitika, bronhodilatatorija i antiasmatika: Asperula odorata, Plantago lanceolata

- Sedativa respiratornog centra: Crataegus monogyna

- Sedativa običnog i velikog kašlja: Clematis vitalba, Papaver rhoeas, Plantago major, Plantago media, Bellis perennis

Droge za lečenje centralnog i perifernog nervnog sistema

- Sedativa i kalmancija: Chelidonium majus, Hypericum perforatum

- Hipnotica i narkotika: Veronica chamaedrys

- Antineuralgici, analgetici, lokalni anestetici: Veronica chamaedrys

- Revulziva irubefaciencija: Helleborus odorus, Urtica dioica

- Dijaforetika: Sambucus nigra

- Antiseboroika: Hedera helix, Urtica dioica, Rubus hirtus

- Paraziticidi i insektifuga: Helleborus odorus, Verbascum phlomoides

Droge koje deluju na autonomni nervni sistem

- Spazmolitika: Chelidonium majus

Droge za lečenje urogenitalnih organa

- Diuretika: Arctium lappa, Daucus carota, Taraxacum officinale, Plantago major, Capsela bursa-pastoris, Prunus avium, Asperula odorata, Sambucus nigra, Pulmonaria officinalis, Agropyron repens

- Antiseptika mokraćnih puteva: Capsela bursa-pastoris, Urtica dioica

- Antihemoragika i uterotonika: Capsela bursapastoris

- Emenagoga: Artemisia vulgaris

Droge za regulisanje prometa materija

- Antiuremika, antiartritika i antireumatika: Urtica dioica, Rumex acetosella, Ranunculus repens

- Depurativa: Viola tricolor, Taraxacum officinale, Arctium lappa

Droge za lečenje kožnih bolesti

- Adstringencija i antiflogistika: Potentilla erecta, Rubus hirtus, Rosa canina, Urtica dioica, Achillea millefolium

- Emoliencija i sedativa: Arctium lappa

- Vulnerarija i sikatrizancija: Hypericum perforatum, Urtica dioica, Sambucus nigra,
Plantago major, Achillea millefolium, Sambucus nigra

- Revulziva i rubefacijencija: Allium ursinum, Helleborus odorus, Urtica dioica

- Dijaforetika: Sambucus nigra

- Antiseboroika: Urtica dioica, Rubus idaeus

- Paraziticidi i insektifuga: Helleborus odorus

Antidijabetici

- Taraxacum officinale, Urtica dioica, Achillea millefolium, Daucus carota

Fitoncidno bilje

- Arctium lappa, Geum urbanum

Galaktagoga

- Daucus carota

Tonika i roborancija

- Urtica dioica, Achillea millefolium, Teucrium chamaedrys, Rumex acetosella, Rosa canina, Rubus hirtus, Potentilla erecta, Taraxacum officinale, Artemisia vulgaris, Verbena officinalis

Droge za popravku ukusa i mirisa raznih lekova

- Rubus hirtus, Rosa canina, Asperula odorata

$\mathrm{Na}$ osnovu obavljene farmakodinamske analize, utvrđeno je da najveći broj lekovitih biljaka obuhvata droge koje deluju na kardiovaskularni, digestivni i respiratorni sistem. Do potpuno identičnog rezultata u pogledu farmakodinamskih svojstava došlo se kod lekovitih vrsta na području Vlasinske visoravni (Ranđelović et al., 2002), pri čemu je na ovom lokalitetu registrovano ukupno 217 lekovitih taksona, što čini oko $22 \%$ od celokupne vaskularne flore. Rezultati farmakodinamske analize sprovedene na području planine Kukavice (Jovanović, 2016) kod 162 lekovite vrste, koje čine oko $26 \%$ od ukupnog broja predstavnika vaskularne flore, pokazuju takođe dominantno prisustvo droga koje deluju na kardiovaskularni, digestivni i respiratorni sistem, kao i značajan procenat droga koje tretiraju urogenitalni trakt $i$ onih koje se koriste za lečenje kožnih bolesti. Na području Besne Kobile zabeleženo je ukupno 192 lekovite vrste, koje čine oko $28 \%$ od ukupnog broja reprezenata vaskularne flore (Đošić, 2016), a rezultati farmakodinamske analize pokazuju dominantno prisustvo droga koje leče kardiovaskularni, respiratorni i digestivni sistem, kao i značajan broj onih koje deluju na centralni i periferni nervni sistem.

ZAKLJUČAK / CONCLUSION 
U okviru osam istraživanih odeljenja na području SP „Šuma Košutnjak“, evidentirano je prisustvo čak 101 lekovite vrste. Činjenica da je floristički diverzitet lekovite flore veoma bogat pruža velike mogućnosti za sakupljanje, sušenje i kasnije komercijalno korišćenje ove veoma značajne privredne sirovine. Treba naglasiti da analize farmakodinamskog potencijala lekovitog bilja na ovom području do sada nisu sprovođene, a to bi svakako u budućnosti trebalo da bude jedan od značajnih pravaca istraživanja kako bi se utvrdila, ne samo brojnost ovih vrsta, već i njihov lekoviti potencijal u smislu lečenja određenog spektra zdravstvenih tegoba. Na bazi tih analiza bi se kasnije mogao definisati okvir za racionalno korišćenje i održivo gazdovanje ovim vrednim populacijama.

Farmakodinamskom analizom, sve lekovite biljke su sistematizovane u 14 grupa. Među njima, najbrojnije su one koje leče kardiovaskularni, digestivni i respiratorni sistem.

\section{LITERATURA / REFERENCES}

[1] Đošić, M. (2016): Analiza flore lekovitih biljaka planine Besne Kobile u jugoistočnoj Srbiji. Master rad u rukopisu, Prirodno-matematički fakultet - Univerzitet u Nišu, str. 49

[2] Igić, R., Vukov, D., Božin, B., Orlović, S. (2010): Lekovite biljke - Prirodni resursi Vojvodine. Vrelo - Društvo za zdravu ishranu i zaštitu životne sredine, Novi Sad, str. 262

[3] Ilić, R., Cerović, O., Gajić, M. (1972): Flora Košutnjaka. Osnovna škola „Josif Pančić“, Beograd, str. 208

[4] Jokanović, D., Vilotić, D., Cvetković, T., Perović, M., Stanković, D., Jović, Đ. (2017): Horološko-fitogeografske karakteristike šumskih ekosistema na području Donjeg Srema (GJ „Kupinske grede“), Ecologica, 87(24), 588592.

[5] Jokanović, D., Cvetković, T., Perović, M., Nikolić, V., Stanković, D., Lekić, J. (2018):
Floristički sastav šuma na području Donjeg Srema - gazdinska jedinica "Kupinske grede“, Ecologica, 92 (25), 905-910.

[6] Jokanović, D., Inđić, P., Petrović, J., Devetaković, J. (2020): Analiza lekovitih biljaka u okviru osam odeljenja na području SP „Šuma Košutnjak", Glasnik Šumarskog fakulteta, 122: 71-90, Beograd.

[7] Jovanović, M. (2016): Analiza flore lekovitih biljaka planine Kukavice u južnoj Srbiji. Master rad u rukopisu, Prirodno-matematički fakultet - Univerzitet u Nišu, str. 49

[8] Kerkez, I., Stanković, D., Vilotić, D., Jokanović, D., Branković, D., Urošević, J. (2019): Istraživanje koncentracije i akumulacije polutanata na području GJ „Lipovica“, Ecologica, 93 (26), 15-20.

[9] Kojić, M., Vilotić, D. (2006): Ekskurziona flora Srbije. Monografija, Šumarski fakultet Univerzitet u Beogradu, str. 387

[10] Ranđelović, V., Mitrović, T., Jušković, M. (2002): Farmakodinamska analiza lekovitih biljaka Vlasinske visoravni. Zbornik radova, VII Simpozijum Flore jugoistočne Srbije i regiona, Odsek za biologiju i ekologiju, Prirodnomatematički fakultet, Univerzitet u Nišu, pp. 111-116.

[11] Sarić, M. (1989): Lekovite biljke SR Srbije. Srpska akademija nauka i umetnosti, Beograd

[12] Stanković, D., Jokanović, D. (2016): Metode fitoremedijacije i održivi razvoj. Ecologica, Beograd, 84 (23), 826-832.

[13] Šarčević-Todosijević, Lj., Petrović, B., Marinković, T., Živanović, Lj., Popović, V. (2018): Pregled lekovitih biljnih taksona razdela Magnoliophyta na lokalitetu Košutnjak. Zbornik radova, 339-344

[14] Tucakov, J. (2014): Lečenje biljem. Novo, izmenjeno i dopunjeno izdanje, Vulkan izdavaštvo D.O.O., Beograd, str. 619. 